\title{
Role of Grit in Secondary School Students' Academic Engagement and Performance: A Meta-Examination
}

\author{
Sofiazianti Saleh, Zakiah Mohamad Ashari, Azlina Mohd Kosnin, Ariffi Suraya Rahmani, Nurul \\ Farhana Zainudin
}

\begin{abstract}
Grit is described as an individual's ability to persevere in the face of challenges while still being passionate towards achieving personal long-term goals. An individual with grit would have the determination and tenacity to ensure that the goals are attained. Certain corroboration suggested that grit is positively linked to a range of academic results, and yet others contended that grit is not significant in defining academic performance. Hence, through meta-analysis, this study aims to determine if grit plays a significant role in secondary school students' academic engagement and performance and which grit-related traits give them passion and perseverance to perform academically well. The meta-analysis of previous researches established that there is a significant link between grit and students' academic engagement and performance. They are: (i) individuals' priorities are determined by types of grit; (ii) school environment that emphasizes value of learning for learning's sake may encourage students to stay interested and focused on certain long term goals; (iii) grit (perseverance of effort) significant impact in predicting academic performance and (iv) grit positively influences individuals taking professional and psychological courses where high levels of grit were demonstrated as they stay in the same course without changing goals for long-term purposes.
\end{abstract}

Index Term: Grit; Secondary School Students; Academic Engagement; Academic Performance.

\section{INTRODUCTION}

Having the passion and persistence for long term and significant goals is identified as grit. Grit is more than just a belief but is a trait that has the capacity of influencing an individual's life as it is a set of necessary conduct and where the individual is knowledgeable and keen in accomplishing a task. How grit separates one person from another is that an optimistic individual can accept changes and adversity, along

Revised Manuscript Received on September 22, 2019

Sofiazianti Saleh, Faculty of Social Sciences and Humanities, Universiti Teknologi Malaysia (UTM),81310, UTM Skudai Johor, Malaysia.sofiazianti2@live.utm.my

Zakiah Mohamad Ashari, Faculty of Social Sciences and Humanities, Universiti Teknologi Malaysia (UTM),81310, UTM Skudai Johor, Malaysia

Azlina Mohd Kosnin, Faculty of Social Sciences and Humanities, Universiti Teknologi Malaysia (UTM),81310, UTM Skudai Johor, Malaysia

Ariffi Suraya Rahmani, Faculty of Social Sciences and Humanities, Universiti Teknologi Malaysia (UTM),81310, UTM Skudai Johor, Malaysia

Nurul Farhana Zainudin, Faculty of Social Sciences and Humanities, Universiti Teknologi Malaysia (UTM),81310, UTM Skudai Johor, Malaysia with learning unceasingly from disappointments. It is a form of mental strength and extrapolative not only in academic-related performance for example academic scores, graduation rate, and retention, but also of non-academic outcomes such as happiness and life fulfilment.

\section{BACKGROUND OF THE PROBLEM}

Being academically excellent is important to individuals, their families and the society. There is a connection between being academically successful and earning good results. Adults, who are academic achievers, would tend to have better career opportunities, stable employment, less dependent on welfare and would have lower tendencies to be involved with unfavorable activities. These groups of individuals are normally healthier, happier and are part of the community.

There are various elements that could affect students' chances to attain and maintain good grades that represent academic performance during their school years. These influences could be pinpointed out specifically if strategies are developed to better student learning and their achievement academically. Test anxiety, managing time, test and academic competencies, and study skills are significant in how an individual would fare in their academic quests.

[1] believed that academic achievement has relationships with internal learning approaches and strategies, while low achievement has relationship with surface learning approach. Apart from that, [2] stated that $25 \%$ of the achievement variance is related to intelligence. However, how individuals differ in personality and motivation has been accepted as one of the crucial predictors important in academic achievement. Furthermore, many studies were undertaken to explore and test various cognitive and non-cognitive factors linked to students' academic achievement. Hence, both cognitive and non-cognitive measures of student growth should be included to ensure effective instruction that can yield positive student reading achievement $[3,4,5]$.

Recent research has turned to non-cognitive constructs and its significance in academic pursuits, for example student attrition, intrinsic and extrinsic factors in student motivation, student self-efficacy, and support services in relation to academic performance and persistence to excel. One such non-cognitive construct is grit, which has been described as determination and desire toward long-term goals [6]. The two-factors included in the non-cognitive skill of grit are 
perseverance and passion in a topic. In short, these researchers believe that individuals with higher degrees of grit may have an increased potential for life success a non-cognitive skill defined as grit has shown some promise in life success.

Grit is generally used to describe the ability to persevere through hardships to meet goals, are rapidly emerging topics in both popular press and peer-reviewed literature. With regards to grit and its role in learning, grit has been introduced officially by psychology related studies as a particular trait that can be observed in students with academic excellence [7]. Grit brings into attention that being passionate and persistent in achieving goals help students in overcoming challenges. [7] discovered that individuals who have more grit would put in more effort to brush up their skills compared to those with less grit.

Several well-known views on grit emphasized that to be successful academically, students must be fully responsible of their own learning processes [8]. There would be tendencies of the students failing and this would be perceived that the students are incompetent, and their failure is not the education system's fault [9]. Traits such as being intelligent and gritty are not born with, but they can be identified and developed. Nevertheless, developing grit means that the individual must have a growth mindset that can be developed through hard work and effective strategies [10].

[7] also states that talent is wasted with the absence of grit. Various schools in United States saw the significance of grit for success and considered in integrating grit as part of their character education curriculum [11]. Made up of two elements, the interest element of grit captures the capability of maintaining interest and the grit's effort elements holds the more extensive notion of being persistent and effort $[4,12]$. [13] also stated that focusing on grit and developing it is possible when it is inculcated early, particularly in school levels. The students would have better commitment towards long-term tasks, be more resilient when faced with more challenges and would be more successful in the real world.

The ability to be gritty is crucial for students to be successful. Grit strives in capturing the ideas commonly related to an individual being resilient, having good self-control, diligent and persistent [14] Students with grit would refuse to give up on their dreams and would be relentless in pursuing their goals. Being gritty is when the student would see failure as part of a positive learning experience and giving the student to strength to keep on trying until the goal is achieved. These students have good understanding on what hard work is, would put in more effort to solve problems and are responsible learners who face both failure and achievements responsibly.

Research on grit in education may still in its infancy; nevertheless, it has been criticized. [15] admitted that measuring girt is aimed to address individual variances but neglects circumstantial influences that might impact accomplishments. [16] criticized grit by pointing out that grit is controversial, often presented as a solution in investigation, or as an ineffectual contrivance when in excess, undermining academic eminence and blaming students' low socio-economic standing for their weak accomplishments, or that it is not always connected to resourceful accomplishment.

The emphases on issues associated to students' achievement in school in academic literature and mass media showed the gravity in those areas, making it inevitable for educators to delve into this issue and study if grit plays a role in students' scholastic engagement and achievement. Hence, study aims in determining if grit plays a significant role in secondary school students' academic engagement and performance and which grit-related traits give them passion and perseverance to perform academically well.

\section{LITERATURE REVIEW}

Numerous studies have investigated intelligence being the factor behind any form of academic performances, however, more studies are necessary to identify if girt does influence how students engage with learning and eventually help them to perform academically. The literature reviews key factors in relation to grit and the factors are: (1) grit; (2) non-cognitive factors and academic success; (3) grit and academic achievement; (4) grit and perseverance.

\section{A. Grit: The definition}

A non-cognitive factor gaining great attention recently among researchers and scholars is grit. Grit, according to [17], is a character's strong point which is used to help an individual to use the full ability to overcome obstacles. University of Pennsylvania's Angela Duckworth researches mainly on grit and has described grit as an act of persevering and being passionate for longstanding objectives [18]. Grit requires individuals to work insistently and enthusiastically when facing difficult goals, very determined and keeps infinite attention despite failure, hindrances and complications, and stages of permanence throughout development.

[19] defined grit as courage and resolve or strength of character. [20] stated that the act of being courageous is a significant trait of grit. This is consistent with [21] whose interpretation of courage is when the rebellious nature of the human spirit gives the individual the strength to hold on to one's values and integrity when faced with adversity or grief. This stemmed from Wong (1995) earlier study as cited in [20] on how courage when facing disappointment or angst as the main factor that led to perseverance and the belief in one's quest led to passion. This strong principle allowed the individual to stay passionate and persistent in the pursuit of achieving goals despite numerous impediments. An individual with high levels of grit would have the strength to keep on track in order to achieve his or her dreams, unlike their counterparts who have lesser grit. This group of low grit individuals would get bored and would eventually give up or shift their attention to something new. In leaders, grit is viewed as part of individual quality and an important success precursor and being excellent within each domain despite being gifted or talented [18,22].

[23] saw grit with regards to having the ability to persevere. In the present, the definition of grit is an inclination to stay interested and putting in more effort with regards to longstanding goals 
[18]. [8] also labelled grit as an act of having passion and committed strongly to one goal and tirelessly working hard to ensure that the goal is achieved. This means that grit is the drive that pushes individuals to not give up before achieving their personal targets and makes individuals commit to difficult tasks and work with great diligence despite the duration the tasks might take to fulfil. These definitions by the researchers have led to grit being compared to devotion, persistence and commitment.

Grit is normally used to predict achievement and accomplishment [15]. [4] commented that unlike IQ (Intelligence Quotient), grit does a more accurate prediction on the number of students' grades and graduating high schools. This again is consistent with findings by [24] whose findings showed that the tendency to succeed on colleges are not predicted by standardized tests but the students' high school grades. This means that students with higher levels of grit would be more successful in their college years. In short, grit, particularly in relation to long-standing goals, involves the will to persevere and having the strong passion to endure the obstacles that might come in the way. A quantitative study by [25] revealed that grit has a high correlation with one of the Big Fives larger personality characteristic of conscientiousness and evidence showed grit is adversely linked to performance on intelligence tests.

In relation to the Big Five, another research by [15] showed notable connection between grit and self-control. Persons with high self-control levels might have the capacity of regulating attention and resisting temptations. However, they might have the persistence to obtain certain life goals. Hence, strong link between grit and self-control do exist but consistencies might be affected when the individuals have different engagement and reaction. Additionally, looking into the real connection between self-control and grit with regards to educational performance and students' individual accomplishment should be taken into consideration.

Grit is rooted in two aspects namely perseverance of effort (PE) and consistency of interest (CI). It is crucial to note that interest is not linked to preference with regards to instantaneous temporary fulfilment, but it is somewhat linked to meaning. According to [26, it is necessary for long-term goal to be not only significant, but to put up with the individual's effort and vigor, it has to be appealing. Both grit $\mathrm{PE}$ and CI are central elements of achievement as the act of $\mathrm{PE}$ is the contributor to an individual's ability to master certain expertise in spite of failure and CI helps in the engagement of deliberate practice to obtain mastery [27].

Perseverance is the key element in being gritty. [28] perseverance as having the will to achieve anything despite the challenges. Various research on grit [4,23,29] proposed that grit is linked with the readiness to risk failure with the intention of succeeding and persevering to achieve significant life goals or example completing arduous physical training, outshining in school academically, and graduating from colleges). [18] also described grit as an element that includes the capacity of working hard to overcome harsh times, putting in effort and being passionate despite failing, hardship and stagnant progresses. Moreover, an individual with grit moves with great tenacity and stay true to their calling unlike individuals who lack grit as they would give up when they feel bored or disappointed.

Duckworth's definition of grit is consistent with studies by [30] whose study looked into passion and perseverance, discovered that both grit subscales are weak predictors of achievement. Therefore, they suggested that grit should be considered in testing variables such as academic preferences and its link to attrition among students. [31] also carried out a study based on Duckworth's definition of grit where they studied if the school environment does influence the way students see learning. They discovered that students are influenced by school environment where students who saw the school as an institution that focuses on mastery performed significantly better than students who perceive their schools as a performance-oriented environment. This supports Duckworth's view of grit where the students' preference could influence their engagement and level of perseverance towards learning

\section{B. Non-cognitive Factors and Academic Success}

Many studies focused on cognitive variables such as memorization, reasoning and eloquence. These cognitive variables are measurable with the use of performance and how well the students accomplish certain tasks. Cognitive factors are important; nevertheless, researchers like [32] and [33] revealed that non-cognitive factors do impact learning. Traits that have no connection with intellect are identified as non-cognitive or soft-skills [34]. Two prevalent non-cognitive predictors' measures are the "Big Five" personality traits and self-regulation [35,36]. In relation to this, studies have been performed and data has been obtained on the significance of non-cognitive factors for children [4,37,38,39]. [8] recommended that the development of these qualities would see the growth of cognitive abilities.

Non-cognitive skills can be categorized into intrapersonal and interpersonal skills. Intrapersonal skills are when an individual has the ability to be resilient, inspired, manage time well, self-control, resourceful and stable emotionally whereas interpersonal skills refer to the individual's ability to work in team, communicate, negotiate and build relationships with others. [40] categorized non-cognitive factors into four categories and they are (i) attitudes and beliefs (i.e., motivation, self-efficacy); (ii) social and emotional qualities (i.e., teamwork, self-regulation); (iii) habits and processes (i.e., time management, learning strategies); and (iv) personality (i.e., openness to experience, agreeableness). This is consistent with [41] who defined non-cognitive factors as behaviours, skills, outlooks, and approaches important in determining how students perform academically and stay persistent at the high school level.

The environments where the students are in daily shape the non-cognitive factors. This means that the students are affected by the things they see, hear and they absorb feelings from their teachers, peers, parents and the community they are in. For learning environment to be conducive and effective in enhancing processes of teaching and learning, classrooms should be linked to learning and encourage students to be persistent in learning $[42,43]$. In short, all these elements, from school to 
parents and teachers, play important roles in shaping the world that the students live in.

Findings from previous literature associated with grit in various areas of learning shows that grit does have significant impact on how well students perform academically. The inferences showed the definition and several aspects of grit, elaborations and to what extent grit could be the factor that gives the students the drive to not give up easily in the face of adversity.

Other studies like [44] and [45] believed that grit plays a role in the evaluation of professions as it focuses on how much the individual knows what he wants or needs. This correlates with the study by [46] who studied the context of grit among employees in Malaysia. They discovered that grit is positively significant on psychological contract of employees where gritty individuals had the tendency to stay true to a course in their pursuit of a personal goal.

Hence, it is imperative that the students grow up in an environment that helps them to develop non-cognitively, where the students feel that what they do matter, the adults around them have confidence in their capabilities and eventually support them to grow at they own pace and become successful in all that they do. Supporting the students in developing their non-cognitive skills, attitude, approaches and behaviours simultaneously improve how they learn and perform academically. The non-cognitive factors linked to academic performance are (i) academic behaviours; (ii) perseverance; (iii) mind-set; (iv) learning strategies; and (v) social skills. [33] argued that academic mindsets were fundamental because it affected perseverance, learning strategies and social skills. Those three factors plus academic mindsets had an impact on academic behaviour. These traits are evident when a student has the penchant of completing school tasks on time and thoroughly, to the best of their abilities, despite diversions, hindrances, or level of challenge. Being academically persistent demands the student to focus on the target prioritizing academic tasks despite any challenges, diversions and enticements.

\section{Grit and academic achievement}

A majority of research attempted to identify if grit could predict academic achievement and other educational-related results. [18] showed grit can significantly predict Intelligent Quotient (IQ) related academic performances. The results showed that individuals with more grit achieve higher academic levels, change careers lesser and saw university students achieving higher Grade Point Averages (GPA) in comparison to their less gritty peers. Grit, when compared to self-control, predicted cadets' summer retention of West Point Military Academy better. Moreover, [4] that grit and life contentment considerably forecast teachers' efficiency measured in terms of students' academic performances. Meta-analysis by [27] showed grit validating reasonable connections with achievement and retention, which strongly correlates with conscientiousness from the Big Five. The meta-analysis showed the accountability grit has difference in academic achievement is more than conscientiousness, which indicates that as a construct, it should be investigated separately.
Grit is believed to be a construct of great influence which is associated to being academically successful. Grit has been discovered to be correlated to academic output and how much students engage with learning activities [47], educational incentive [23,48], educational attainment [49], ability to persevere when challenged [25], hours spent on studying [50], postgraduate students [51], students' retention [27].

[52] investigated educational accomplishment at principally White institutions and established that grittier black males with attained better scores than their same-race male counterparts who are less gritty. Based on the same study, grit can positively predict college grades explaining the correlation between college grades and high school GPA and American College Testing (ACT) scores. Likewise, [53] discovered the undergraduate students' GPA was forecasted by the self-report grit total score, and [49] stated that the high academic performance of student pharmacists in America was predicted by grit-total score. [54] students in Taiwan who have strong grit self-report higher academic performance and are more satisfied academically.

Four research investigating grit's ability to be used to predict beyond intellect and behaviour with regards to how learners perform academically were carried out and grit gave a prediction on an exclusive variant pertaining to performance on Academic Diligence Task that measured academic persistence, the amount of time being spent on certain assignments or output in solving problems among high school students after agreeableness is controlled [55]. Balancing the results were a study by [56], whose investigation if non-cognitive individualities have gradual analytical capability over intelligence and conscientiousness pertaining to academic accomplishment. Grit has a moderate correlation with academic achievement conditions, for example GPA, science and language marks.

Grit needs to be investigated more as several researchers found that there is a correlation between grit and academic retention. [23] found grit positively correlates with being motivated in school and academic conscientiousness. This means that grit can be used to predict if a student would graduate or if he or she will stay in school. In short, grit predicts academic retention which goes beyond popular traits like intellect and demography.

With regards to preparing individuals for career, [57] forecasted that grit is prominent when individuals prepare themselves for working life and in circumstances where the Big Five personality characteristics are specific particularly in relation to main career changes. However, there was other research that investigated the link between grit and examination scores and found no connection between the variables. A study by [58] pointed out that grit did not contribute significantly to academic related results. It, on the other hand, controls how the students previously performed academically which could have been a factor related to how gritty the student was.[59] highlighted that there was no correlation between grit and first year college students' grades and [60] stated that grit did not predict school outcomes even after the Big Five personality traits were

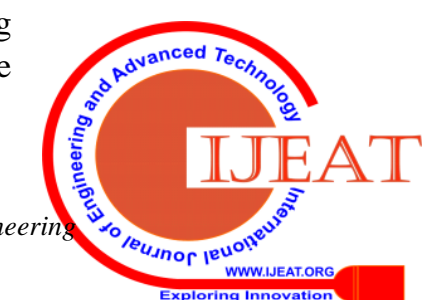


controlled. In terms of school subjects, [58] discovered that there is no correlation between grit and Eight grade students' English or Mathematics test results. These findings could suggest that in the context of grit and academic performance, grit may have a minor effect on the students' academic performance due to the students' traits and results. Despite the assumption that grit is minor in an academic setting, it is still worth investigating as there is a need to understand if grit does help with academic performance especially in primary and secondary education.

Duckworth's definition of grit is consistent with studies by [29] whose study looked into passion and perseverance, discovered that both grit subscales are weak predictors of achievement. Therefore, they suggested that grit should be considered in testing variables such as academic preferences and its link to attrition among students. [30] (Park et al., 2018) also carried out a study based on Duckworth's definition of grit where they studied if the school environment does influence the way students see learning. They discovered that students are influenced by school environment where students who saw the school as an institution that focuses on mastery performed significantly better than students who perceive their schools as a performance-oriented environment. This supports Duckworth's view of grit where the students' preference could influence their engagement and level of perseverance towards learning.

The literatures reviewed suggest that grit might be significant in keeping students engaged and committed with learning and education. There could be a probability there would be a minor connection between grit and academic results, but it is crucial that more research is needed to further substantiate these earlier findings.

\section{Grit and Perseverance}

[13] emphasized the importance of passion and perseverance in grit. She is of the opinion that in circumstances were the individual who is in pursuit of a long-term goal that is in line with what their interests and they have feel strongly about, the individual would move forward regardless of obstacles and attain the goal. Her views are substantiated by [61] who stated that these behaviours are consistent with academic high achievers who persevered through all challenges and obstacles.

\section{METHODOLOGY/MATERIALS}

This meta-analysis determines to find out if grit is significant in students' academic engagement and their academic performances. The analysis also investigates if there are any specific grit-related traits that do have influence on students' learning preferences or behaviour. Keywords used in this search process of prior research linked to grit and academic achievement are grit, students' academic performances, grit and students' academic performances and grit-related traits. The literature was attained through online database such as Science Direct, Elsevier and Education Resources Information Centre (ERIC). The criteria used in the search for related researcher are as follows; (1) research on grit and academic performance; (2) grit and intelligence; (3) studies between 2006 to date and (4) specific studies on significance of grit and its significance in the field of education. The qualitative analysis on the role of grit in aspects of students' engagement and academic performance revealed noteworthy findings and the literature corroborating the findings are summarized the next section.

\section{RESULTS AND FINDINGS}

Table 1 The Meta-Analysis Grit's role on Secondary school students' academic engagement and academic performance.

Grit's role on

Secondary school

students' academic

engagement and Explication Study

academic

performance

$\begin{array}{lll}\begin{array}{l}\text { Individuals' } \\ \text { priorities are } \\ \text { determined by types } \\ \text { of grit }\end{array} & \begin{array}{l}\text { Types of grit } \\ \text { correlates with } \\ \text { how individuals } \\ \text { prioritise their } \\ \text { task or goals }\end{array} & \begin{array}{l}\text { Duckworth et.al } \\ \text { (2007); Duckworth } \\ \text { and Gross (2014); } \\ \text { Crede et al., (2016); } \\ \text { Kannangara et.al } \\ \text { (2018) }\end{array}\end{array}$

School

environment that

emphasizes value

of learning for

learning's sake

may encourage

students to stay

interested and

focused on certain

long-term goals

\section{Correlation}

between school

environment

and grit which

leads to

students'

engagement

with tasks and

learning

\section{Grit (Perseverance}

of Effort -PE)

Correlation

3

significant impact

in predicting

related trait

academic

(PE) and

academic

performance

performance

Earthman \& Lemaster (2009); (Bouslama \&

Kalota, 2013)

(Vaughn, 2016);

Duckworth (2016);

Park et.al (2018)

Grit was found to

have a positive and significant impact

on psychological

course and

professionals as

individuals

4 demonstrating

high levels of grit

would likely stay

on the same course

in pursuing an

unchanging goal

over the long run.

Duckworth et.al

(2007); Singh \& Jha

(2008);

Eskreis-Winkler,

Gross, \& Duckworth

(2014); Hodge et.al

(2017); Kannangara et.al (2018)

Correlation

between grit and gritty individuals taking professional courses who tend to stay on the same course

to achieve a

long-term goal

\section{Von Culin,}

Tsukayama, \&

Duckworth (2014);

Duckworth (2016);

Ramasamy \& Mun

(2017); Hammond

(2017); Palisoc et al., 2017

Based on the study's meta-analysis, four factors are identified:

\section{A. Individuals' priorities are determined by types of grit}

The findings in relation to types of grit showed that the grit levels in different individuals are influenced their priorities. Individuals would have the tendency of prioritizing goals that is currently more valued and another corresponding to goals of more lasting worth. 
Both types of goals are taken into consideration when achieving a goal whose rewards are enduring. Hence, grit plays a role when the individual prioritises the tasks based on the rewards obtained at the end of the day.

\section{B. School environment that emphasizes value of learning for learning's sake may encourage students to stay interested and focused on certain long-term goals}

Learning environment in school is seen as another factor that helps to inculcate grit in students. A grit-enhancing academic setting enables students to see the significance of learning and entice them to take part actively in the process of teaching and learning. Student engagement is where the students are impacted by activities importance to their academics and allows the students to learn exceptionally well.

\section{Grit-related trait (Perseverance of Effort)}

Perseverance of effort (PE or Perseverance) is a grit-related trait is identified by several researchers as a contributing factor as it represents the individual's tendency of working hard and putting in more effort despite disappointments and failures.

\section{Grit and Professionals}

Among those taking professional courses and those currently in the workforce, grit helps in the enhancement of competencies and abilities. A professional with positive mindset would have the capacity of coping with challenges and accepting changes while learning from setbacks.

\section{E. Discussion}

Based on the research analysed, grit appears to have a certain form of influence on areas of high attrition for example education, military and professional positions. The significance in these findings is that grit may have a role in the reasons behind students' engagement with teaching and learning processes and how they would perform academically. The findings showed that strong grit levels mean that the individual has strong determination. Individuals would have stronger grit when they practice more to improve themselves. This shows that these gritty individuals would face their challenges and fears head on and would not back down until the goals are accomplished.

\section{CONCLUSION}

Study on the role of grit and academic achievement and engagement among secondary school students is necessary as teachers and policymakers would be able to use grit to help students to stay in school, engage actively and eventually do well in the crucial academic areas. The learning environment in schools can be improved further to create a setting where the students learn the values of learning, know what they want in life and not see education as a short-term engagement.

\section{ACKNOWLEDGEMENTS}

This work was supported by Universiti Teknologi Malaysia, Ministry of Education Malaysia and Research University Grant, vot no. Q.J130000.2531.16H60

\section{REFERENCES}

[1] N. A. W Nordin, Rohaya \& Ainuddin Dahlan, Nadia. Approaches to Learning among Trainee Teachers: Malaysian Experiences. Procedia Social and Behavioral Sciences, 284-293. 2013.

[2] C.-F. LO. Is There a Relationship between High IQ Scores and Positive Life Outcomes? A Critical Review. Psychology, 8, 627-635. 2017

[3] P. R.Sackett, M. J.Borneman, B. S. Connelly. High stakes testing in higher education and employment: Appraising the evidence for validity and fairness. American Psychologist, 63, 215-227.2008.

[4] A. L. Duckworth, P. D Quinn, M. E. P. Seligman, Positive predictors of teacher effectiveness. The Journal of Positive Psychology, 4, 540-547.2009.

[5] B. Kallick, Allison, Zmuda. Orchestrating the Move to Student-Driven Learning. Educational Leadership. Vol.74, No.6. 53-57. 2017.

[6] K. Von Culin, E. Tsukayama, A. L. Duckworth Unpacking grit: motivational correlates of perseverance and passion for long-term goals. Journal of Positive Psychology. 2014.

[7] A. Duckworth Grit: The power of passion and perseverance, New York, NY, US, Scribner/Simon \& Schuster. 2016.

[8] P. Tough How children succeed: Grit, curiosity, and the hidden power of character., New York, NY, Houghton Mifflin Harcourt Publishing Company.2013.

[9] O. Patterson, E. Fosse The cultural matrix: Understanding black youth., Cambridge, MA, Harvard University Press. 2015.

[10] A. Hochanade, D. Finamore. Fixed and Growth Mindset in Education and How Grit Helps Students Persist in The Face Of Adversity. Journal of International Education Research - First Quarter 2015, 11 2015

[11] D. A.Vaughn, . Grit in the Classroom. (Master of Arts (MA)), Loyola University Chicago, 2016

[12] A. L. Duckworth, C. Peterson, M. D. Matthews, D. R. Kelly. Grit: Perseverance and passion for long-term goals. Journal of Personality and Social Psychology, 92(6), 1087-1101. 2007

[13] A. Duckworth . Grit: The power of passion and perseverance. New York, NY, US: Scribner/Simon \& Schuster.2016

[14] J. Bashant. Developing grit in our students: why grit is such a desirable trait, and practical strategies for teachers and schools. Journal for Leadership and Instruction, 13, 14-17.2014.

[15] A. Duckworth, J. J. Gross. Self-Control and Grit: Related but Separable Determinants of Success. 2014.

[16] C.Anderson, A. Cureton Turner, D.R. Heath, C.M Payne. On the Meaning of Grit...and Hope...and Fate Control...and Alienation....and Locus of Control....and...Self-Efficacy....and...Effort Optimism....and.... Urban Review [Online].2016.

[17] M. Soutter, S. Seider. College access, student success, and the new character education. Journal of College \& Character, 14, 351-356.2013.

[18] A. L Duckworth, C. Peterson, M.D. Matthews, M, D.R Kelly. Grit: Perseverance and passion for long-term goals. Journal of Personality and Social Psychology, 92(6), 1087-1101. 2007.

[19] Oxford Dictionaries (2014)

[20] M. M. Perlis. 5 characteristics of grit-how many do you have? Retrieved from https://www.forbes.com/sites/margaretperlis/2013/10/29/5-characteri stics-of-grit-what-it-is-why-you-need-it-and-do-you-have-it/\#21 a65b 8b4f7b. 2017.

[21] P. T. P. Wong. The positive psychology of grit: The defiant power of the human spirit. PsycCRITIQUES, 60(25).2015

[22] A. L. Duckworth, D. S. Yeager. Measurement matters: Assessing personal qualities other than cognitive ability for educational purposes. Educational Researcher, 44(4), 237-251.2015.

[23] L. Eskreis-Winkler, E.P. Shulman, S.A. Beal. The grit effect: predicting retention in the military, the workplace, school and marriage. Frontiers in Psychology, 36(5).2014.

[24] W. G. Bowen, M.M. Chingos, M.S. Mcpherson. Crossing the Finish Line, Princeton, NJ, Princeton Univ. Press. 2009.

[25] Lucas, G., Gratch, J., Cheng, L., \& Marsella, S. (2015). When the Going Gets Tough: Grit Predicts Costly Perseverance (Vol. 59)

[26] M.Perez. Obtaining Academic Success: Nurturing Grit in Students. Journal of Interpersonal Relation, Intergroup Relations and Identity, 8 56-63.2015. 
[27] M Credé, M.C.Tynan, P. D. Harms. Much ado about grit: A meta-analytic synthesis of the grit literature. Journal of Personality and Social Psychology, 113.2017.

[28] K. Singh, \& S.D. Jha. Positive and negative affect, and grit as predictors of happiness and life satisfaction. Journal of the Indian Academy of Applied Psychology, 34, 40-45.2008.

[29] C. Robertson-Kraft, A. Duckworth. True Grit: Trait-Level Perseverance and Passion for Long-Term Goals Predicts Effectiveness and Retention Among Novice Teachers (Vol. 116). 2014.

[30] R. Steinmayr, A. F.Weidinger, A.Wigfield. Does students' grit predict their school achievement above and beyond their personality, motivation, and engagement? Contemporary Educational Psychology, 53, 106-122.2018.

[31] D. Park, A.Yu, R.N. Baelen, E.Tsukayama, A. L. Duckworth Fostering Grit: Perceived School Goal-Structure Predicts Growth in Grit and Grades. 2018.

[32] L. Stankov. Unforgiving Confucian culture: A breeding ground for high academic achievement, test anxiety and self-doubt? (Vol. 20). 2010 .

[33] C. A Farrington, M. Roderick, E. Allensworth, J.Nagaoka, T. Seneca Keyes, D.W. Johnson. Teaching adolescents to become learners: The role of noncognitive factors in academic performance. A critical literature review. Chicago, IL: Consortium on Chicago School Research. 2012.

[34] C. Adams. Soft skills pushed as part of college readiness. Education Week. 2012.

[35] Kitsantas, A., Winsler, A., \& Huie, F. (2008). Self-regulation and ability predictors of academic success during college: a predictive validity study. Journal of Advanced Academics, 20(1), 42-68.

[36] L.A. Sparkman, W.S. Maulding, J.G. Roberts. Non-cognitive predictors of student success in college (Vol. 46). 2012.

[37] A. Furnham, J. Monsen, G. Ahmetoglu. Typical intellectual engagement, Big Five personality traits, approaches to learning and cognitive ability predictors of academic performance.The British journal of educational psychology. 79 . 769-82. 10.1348/978185409X412147.2009.

[38] K. Parviz, M. Sharifi. Relationship between cognitive and metacognitive strategies and educational success in urban and rural high school students. Educ Strategy Med Sci 4, 1-6.2011.

[39] M. Silles. The intergenerational effects of parental schooling on the cognitive and non-cognitive development of children, Economics of Education Review, 30, 258-268. 2011

[40] A.A Lipnevich, C. Maccann, R.D. Roberts Assessing non-cognitive constructs in education: A review of traditional and innovative approaches., New York, NY, US, Oxford University.2013.

41] J. Nagaoka, C.A. Farrington, M. Roderick, E. Allensworth, T.S. Keyes, D.W. Johnson, N.O. Beechum. Readiness for College: The Role of Noncognitive Factors and Context. Voices in Urban Education, 38.2013.

[42] G.I. Earthman, L.K. Lemasters. Teacher Attitudes about Classroom Conditions. Journal of Educational Administration, 323-335.2009.

[43] F. Bouslama \& F. Kalota. Creating smart classrooms to benefit from innovative technologies and learning space design. International Conference on Current Trends in Information Technology (CTIT), 102-106.2013.

[44] D. Hammond. Grit: An important characteristic in learners. Currents in Pharmacy Teaching and Learning. 9 . 10.1016/j.cptl.2016.08.048.2016.

[45] R. Fite, M. Huntoon Lindeman, A. Rogers, E. Voyles, A. Durik. Knowing oneself and long-term goal pursuit: Relations among self-concept clarity, conscientiousness, and grit. 108. 191-194. 10.1016/j.paid.2016.12.008.2017

[46] S. Ramasamy, S.M.Yu. Mediating Effect Of Utilisation Of Emotion On The Relationship Between Grit And Psychological Contract. Jurnal Psikologi Malaysia, 31, 64-83.2017

[47] B. Hodge, B. Wright, P. Bennett. The Role of Grit in Determining Engagement and Academic Outcomes for University Students. Research in Higher Education, 59, 448-460.2017.

[48] D.R. Kelly, M.D. Matthews \& P.T Bartone. Grit and hardiness as predictors of performance among west point cadets. Military Psychology, 26, 327-342. 2014

[49] A. N. Pate, N. Payakacha, T.K. Harrell, K.A. Pate, D.J. Caldwell, A. M Franks. Measurement of Grit and Correlation to Student Pharmacis Academic Performance. American journal of pharmaceutical education, 81, 105-105.2017.

[50] T. M. Cross. The Gritty: Grit and Non-traditional Doctoral Studen Success. 2014.
[51] A.J.L. Palisoc, R.R. Matsumoto, J. Ho, P.J. Perry, T.T. Tang, E. J. Ip. Relationship Between Grit with Academic Performance and Attainment of Postgraduate Training in Pharmacy Students. American journal of pharmaceutical education, 81, 67-67.2017.

[52] T. Strayhorn. What Role Does Grit Play in the Academic Success of Black Male Collegians at Predominantly White Institutions? Journa of African American Studies. 18. 10.1007/s12111-012-9243-0.2014.

[53] P. Akos, J. Kretchmar. Investigating Grit at a Non-Cognitive Predicto of College Success. The Review of Higher Education, 40(2), 163-186. doi: 10.1353/rhe.2017.0000. 2017.

[54] C.Y Chang, C.L Lin. Personality and Family Context in Explaining Grit of Taiwanese High School Students. EURASIA Journal of Mathematics, Science \& Technology Education, v13 n6 p2197-2213. 2017

[55] B.M. Galla, B.D. Plummer, R.E. White, D. Meketon, S.K. D'mello, A.L. Duckworth. The Academic Diligence Task (ADT): Assessing Individual Differences in Effort on Tedious but Important Schoolwork. Contemporary educational psychology, 39 314-325.2014.

[56] B. Dumfart, A.C. Neubauer. Conscientiousness is the most powerful noncognitive predictor of school achievement in adolescents. Journal of Individual Differences, 37, 8-15.2016.

[57] S. Lee, Y.W. Sohn. Effects of grit on academic achievement and career-related attitudes of college students in Korea. Social Behavior and Personality, 45, 1629-1642.2017.

[58] P.L. Bazelais, J. David, T. Doleck. How Does Grit Impact College Students' Academic Achievement in Science? European Journal of Science and Mathematics Education, 4, 33-43.2016.

[59] S. B. Stewart. Grit and Self -Control as Predictors of First-Year Student Success. Degree of Doctor of Philosophy in Public Policy, University of Southern Maine. 2015.

[60] Z. Ivcevic, M. Brackett. Predicting school success: Comparing Conscientiousness, Grit, and Emotion Regulation Ability. Journal of Research in Personality, 52, 29-36.2014.

[61] C. S., Kannangara, R. E Allen, G. Waugh, N. Nahar, S. Z. N., Khan, S. Rogerson, J. Carson. All That Glitters Is Not Grit: Three Studies of Grit in University Students. Frontiers in psychology, 9, 1539-1539. 2018

\section{AUTHORS PROFILE}

My name is Sofiazianti Saleh, I am affiliated with Faculty of Socia Sciences and Humanities, Universiti Teknologi Malaysia (UTM),81310, UTM Skudai Johor, Malaysia. My area of interest is academics and learning. For more details please email me at sofiazianti2@live.utm.my

I ma Zakiah Mohamad Ashari,my affiliation is with Faculty of Social Sciences and Humanities, Universiti Teknologi Malaysia (UTM),81310, UTM Skudai Johor, Malaysia. My area of interest is student's education and development.

Azlina Mohd Kosnin, is currently affiliated with Faculty of Social Sciences and Humanities, Universiti Teknologi Malaysia (UTM),81310, UTM Skudai Johor, Malaysia. My area of interest is education.

I am Ariffi Suraya Rahmani, currently affiliated with Faculty of Social Sciences and Humanities, Universiti Technology Malaysia (UTM),81310, UTM Skudai Johor, Malaysia. My area of interest is educational development.

I am Nurul Farhana Zainudin, Faculty of Social Sciences and Humanities, Universiti Teknologi Malaysia (UTM),81310, UTM Skuda Johor, Malaysia. My area of interest is education. 